Research Notes

\title{
Could the Hybrid form of Lecturing and Active Learning be used as a Curricular Tool for Medical Education of Immunology in Algeria?
}

\author{
${ }^{1}$ Kheir Eddine Kerboua and ${ }^{2}$ Kamal Djenouhat \\ ${ }^{1}$ Laboratory of Immunology, Faculty of Medicine Ouargla, Algeria \\ ${ }^{2}$ Laboratory of Immunology, Faculty of Medicine Algiers, Algeria
}

\author{
Article history \\ Received: 28-09-2019 \\ Revised: 25-10-2019 \\ Accepted: 05-12-2019 \\ Corresponding Author: \\ Kheir Eddine Kerboua \\ Laboratory of Immunology, \\ Faculty of Medicine Ouargla, \\ Algeria \\ Email: k.k.eddine@gmail.com
}

\begin{abstract}
Lecturing has been the predominant mode of instruction since universities were founded in Western Europe over 900 y ago and still the sole method of instruction in the developing countries. However, claiming that adopting a specific new method will have reproducible results regardless the population's characteristics is simply not possible. In this study, we sought to demonstrate that hybrid form of lecturing and active learning could be used as a curricular tool for medical education, specifically for immunology, to enhance learning performance and promote development of test-taking and metacognitive skills among students from the faculty of medicine of Oran, West Algeria. One hundred fifty four 2nd year dental medicine students were analyzed for several parameters to assess classical and active learning methods. The median comparison showed a marked improvement of exam scores in groups taken Brainstorming (BS) and Problems-Based-Learning (PBLs) $(\mathrm{p}<0.00)$. BS was associated with the control of immunology learning $(\mathrm{p}=0.044)$, students active participation $(\mathrm{p}=0.023)$, practical knowledge $(p=0.011)$ and knowledge organization of the $(p=0.045)$. Herein, we confirm that the active learning is widely accepted by Algerian medical student as complementary tool to the lecturing. We propose that hybrid formula of these two approaches is needed to work cooperatively to solve problems and develop solutions.
\end{abstract}

Keywords: Developing Countries, Non-Classical Teaching Methods, Problem-Based Learning, Brainstorming Learning, Quiz Learning, Metacognitive Skills, Exam Scores

\section{Introduction}

Teaching medical immunology is a major challenge for medical schools around the world. With the succession of the Nobel Prizes of Medicine in immunology and the implication of this science in the most serious public health problems, more and more curiosity is raising among people, patients, students and scientists and this makes its teaching a great responsibility for the medical faculties. Several researches raise questions about the real benefit of continuing to use the classic method based only on lectures or strengthening it with active methods called non-classical methods (NCMs).

\section{Objective}

This study aimed to measure the impact of three teaching NCMs (Problem-Based Learning -PBL-,
Brainstorming -BS- and Quiz-based Learning -QL-) in immunology learning process and to examine whether the hybrid learning strategy (classical learning supported by active methods) could be used to improve our population's students performance on summative assessments and to promote knowledge retention and development of metacognitive, problem-solving and interpersonal skills.

\section{Materials and Methods}

An Interventional study was designed in the faculty of medicine of Oran (West Algeria) for the $2^{\text {nd }}$ year dental medicine students $(n=154)$ during the $2^{\text {nd }}$ semester of 2016. A series of optional sessions of active learning by the NCMs was introduced as following (Fig. 1 and Table 1): lectures (LM) followed by BS learning followed by PBLs followed by QL. 
Table 1: Detailed description of the operational organization chart of this study (photo available in jpg)

\begin{tabular}{|c|c|c|}
\hline & Learning methods & Learning mode and dominant core element \\
\hline Phase 1 & lecture-based learning & Deep and broad foundation of factual knowledge \\
\hline Phase 2 & Brainstorming & $\begin{array}{l}\text { Invest in the recall of information from the sub-conscious with free access to } \\
\text { documents and teaming with commitment of the student in the learning process } \\
\text { via elaboration of mind mapes and inter and intra-groupsoral communication }\end{array}$ \\
\hline Phase 3 & $\begin{array}{l}\text { Individual quiz immediately followed } \\
\text { by the same quiz but in group }\end{array}$ & Evaluation of short-term retention and decrease misconception by teaming \\
\hline Phase 4 & Problem-based learning & $\begin{array}{l}\text { Real scenarios from the professional or research of socio-economic word with } \\
\text { group work and oral communication }\end{array}$ \\
\hline Phase 5 & $\begin{array}{l}\text { Individual quiz immediately followed } \\
\text { by the same quiz but in group }\end{array}$ & Evaluation of short-term and decrease misconception by teaming \\
\hline Phase 6 & Final & Evaluation of academic achievement \\
\hline
\end{tabular}

\begin{tabular}{|c|}
\hline $\begin{array}{c}13 \text { Classes at the amphitheater during } 12 \mathrm{H} \\
06 \mathrm{H} \text { for courses of innate immunity } 06 \mathrm{H} \text { for } \\
\text { courses of adaptive immunity }\end{array}$ \\
\hline Followed by \\
\begin{tabular}{|c|} 
The exams of the College of Lyon $2011,12,13,14$ \\
12 scenarios that concern all courses
\end{tabular} \\
\hline Followed by \\
\hline 01 Problem Based Learning Session $(02 \mathrm{H})$ \\
12 Issues that affect all courses \\
\hline Followed by \\
01 session of Quiz Learning $(02 \mathrm{H})$ \\
13 MCQs that concern all courses \\
\hline Followed by \\
\hline Final evaluation by an official exam \\
corrected by the Docimology Department \\
of the Faculty of Medicine of Oran
\end{tabular}

Fig. 1: Organizational chart of the hybrid teaching method adopted in this study

The outcome of each phase was measured by two assessments: (1) evaluation of academic achievement by multiple-choice questions and (2) assessment of NCMs parameters by students themselves on 10-point Likert scale survey for each NCMs. The analysis focused on three intriguing questions: Do these different NCMs work synergistically? Do NCMs increase test scores? Do these techniques reduce failure rates? Lectures, NCMs, exams and questionnaires of this study were made in French, the official language of the high education of all the former French colonies. All the educational resources have been put online in a slideshare account (https://www.slideshare.net/KheirEddineKERBOUA/pres entations) and to streamline the two-way communication we have created a teaching page on facebook, the most used social network in this geographical area (https://www.facebook.com/ImmunologyLearning).

Data were collected in MS Excel and analyzed by the SPSS software with a significance level of $5 \%$.

\section{Results}

84 students out of $154(55.2 \%)$ agreed to participate in the study with a sex ratio of 3 . Initially, only $46 \%$ of the students declared to have retained $20 \%$ or $30 \%$ of the courses by LM with an interest rate of $33 \%$ in immunopathology, 29\% in immunobiology and $14.5 \%$ in the research side of immunology (Table 2). The student's assessment of LM on the likert scale revealed that this classical method failed to achieve 6/19 educational objectives with a median $<6$ points (time allocated for discussion, active student involvement, lack of interactivity with the teacher, course density, practical knowledge, data redundancy. At the end of the LC a questionnaire consisting of 15 items to probe the motivation of students for adding NCMs in their learning process was administered to show that $45.9 \%$ of students claim more interactivity with the teacher, $54.1 \%$ of clinical cases, $54.1 \%$ of working in small groups on knowledge translation, $63.9 \%$ prefer thinking than learning by heart (Table 3). The BS phase analysis revealed that out of 15 parameters, 4 had a median $<8$ points, namely: Prior knowledge reactivation, individual contribution into a group, development of critical thinking and playfulness (Fig. 2). BS was associated with the control of immunology learning $(p=0.044)$, students active participation $(p=0.023)$, practical knowledge $(p=$ $0.011)$ and knowledge organization of the $(p=0.045)$. The median comparison showed a marked improvement of exam scores in groups taken BS and PBLs $(p<0.00)$ (Fig. $2)$. PBLs allowed to gain on knowledge control $(71.43 \%)$, development of the critical spirit $(100 \%)$, interest of the collective intelligence over the individual one (64.28\%). QL has shown a significant contribution on the final exam grade $(p<0.000)$. PBLs combination with QL significantly improved the final exam score $(p=0.002)$. Nonetheless, we found that the final score is explained at $24.8 \%$ by the number of attendance to the lectures $\left(R^{2}=0.287\right)$. On the occasion of the review session for the postponed students from the regular session examination (the median of their score was 7 out of 20), a survey was administered and showed that this failure was associated essentially to the preliminary idea that immunology is 
complicated $(68.75 \%)$, procrastination in obtaining educational materials $(68.75 \%)$; course density in the day when immunology is taught $(50 \%)$. Data analysis of our Slideshare sharing all our lectures and PBL in the net showed that the highest percentage of consultations was for the PBLs.

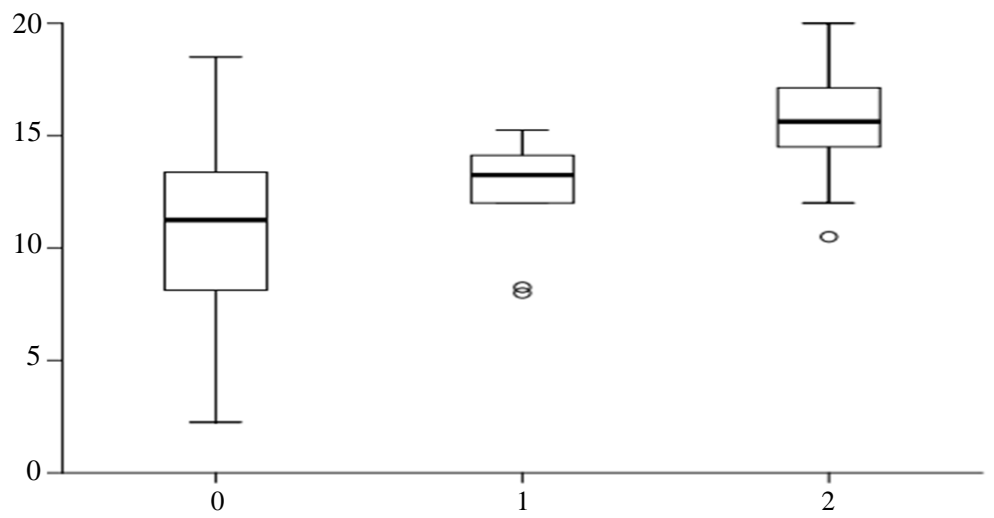

Fig. 2: Impact of incorporating non-classical methods on the final score; 0: neither PBL nor Brainstorming; 1: PBL without Brainstorming; 2: Quiz + Brainstorming + PBL

Table 2: Basic characteristics of the studied population (photo available in jpg)

\begin{tabular}{|c|c|c|c|c|}
\hline Age $($ mean $+\mathrm{SD})$ & $20.523 \pm 0.601$ & & & \\
\hline Sex & Female 57.41 & Male 20.37 & & \\
\hline Baccalaureate $(\%)$ & Mathematics (5.9\%) & Science of nature an & d life $(55.1 \%)$ & \\
\hline Residence $(\%)$ & Family home 3.48 & Campus 38.89 & & \\
\hline Internet access (\%) & Always 12.96 & Partial 27.78 & Rarely 25.92 & No access 9.26 \\
\hline Lessons obtaining (\%) & Slideshare 16.67 & FaceBook 31.48 & Photocopy 29.63 & \\
\hline Lecture's retention at the amphitheater (\%) & $10 \%(11.11)$ & $20 \%(20.37)$ & $30 \%(25.92)$ & $40 \%$ (17) $50 \%(2)$ \\
\hline Preference in the slides content $(\%)$ & Texts 14.81 & Schemes 9.26 & Explanations 50 & \\
\hline I prefer to have a book $(\%)$ & Text Book 11.11 & Video book 66.67 & & \\
\hline I prefer that the time allocated to the course be (\%) & Reduced 61.11 & Extension 5.5 & & \\
\hline What themes did you interest in? (\%) & Mechanistic 29 & Pathology 33 & research side 14.5 & \\
\hline & Very weakly & Weakly & Strongly & Very strongly \\
\hline $\begin{array}{l}\text { The contribution of high school courses of immunology in } \\
\text { understanding }(\%)\end{array}$ & & 29.63 & 35.18 & 11.1 \\
\hline $\begin{array}{l}\text { Contribution of immunological knowledge to dental medical } \\
\text { practice }(\%)\end{array}$ & & 27.77 & 40.74 & 3.7 \\
\hline $\begin{array}{l}\text { Use of immunology knowledge to understand the dental } \\
\text { pathology }(\%)\end{array}$ & 7.41 & 22.22 & 42.6 & 5.55 \\
\hline $\begin{array}{l}\text { immunology motivated me to take the path of finding an } \\
\text { anti-caries vaccine }(\%)\end{array}$ & 25.93 & 20.37 & 25.93 & 5.55 \\
\hline
\end{tabular}

Table 3: Student motivation survey prior to incorporate of the non-classical methods in their learning process of Medical Immunology (photo available in jpg)

\begin{tabular}{lrr}
\hline Survey investigating student preferences & Yes (\%) & No (\%) \\
\hline I prefer to have tutorials with corrections & 37.7 & 31.15 \\
I want more interactivity with the teacher & 45.9 & 44.3 \\
Were the themes treated more attractively? & 45.9 & 19.68 \\
Has the teaching of fundamental immunology opened you to pathology? & 60.7 & 22.95 \\
Do you think immunology could have dental applications? & 29.5 & 54.1 \\
I want to personal research independently of my teacher. & 54.1 & 6.56 \\
I wish to apply theoretical knowledge in immunology to clinical cases & 63.9 & 3.3 \\
I want to work in small groups led by our teacher in addition to lectures & 49.2 & 13.12 \\
I prefer to think more than to learn by heart & 36.1 & 4.99 \\
I prefer to memorize more than to think & 41.0 & 63.93 \\
Do the introductory slides of each course seem useful to you? & 21.3 & 14.75 \\
Does the interactivity and the discussion created by Dr. Kerboua seem sufficient to you & 31.15 \\
I want that I pushed myself to be more engaged in the course than to passively follow it & 14.8 & 16.39 \\
Do you want to work in immunology research teams in the future? & 44.26 \\
Do you want to teach immunology to dentists in the future? & 52.46 \\
\hline
\end{tabular}




\section{Discussion}

Analysis of the final exam scores and the parameters of the different NCMs indicate that the students who benefited the most from the active learning are those enrolled in BS + PBLs group, because this group had the greatest improvement in skill performance and the greatest decrease in the negative parameters. However, we also showed that attendance at lectures was decisive in the final grade. Our research is consistent with previous studies that showed the contribution of Active Learning (AL) in improving cognitive performance and exam's scores (Freeman et al., 2014; Walker et al., 2008; Pyburn et al., 2014). We confirm the results of Freeman et al. (2014) that AL constitutes an approach that improves student performance and learning outcomes. We found that AL has a greater impact on students' cognitive proficiency, which is consistent with the results of previous investigators (Haukoos and Penick, 1983; Martin et al., 2007; Cordray et al., 2009; Jensen et al., 2015). Our study tried to respond to the concern of the medical faculty communities to redesign our courses into dynamic, student-centered learning domains that engage our students in researchbased learning, problem solving and enhanced personnel development (Wood, 2003; $\mathrm{Ma}$ and $\mathrm{Lu}$, 2019; LaNoue et al., 2019).

\section{Conclusion}

Most of our students have endorsed the use of NCMs to provide a holistic understanding of immunological concepts, helping to schematically consolidate knowledge and elucidate the complex concepts that characterize the teaching of Medical Immunology. More studies are desirable in other medical specialties to better adapt these new methods in our Algerian faculties of medicine.

\section{Author's Contributions}

All authors equally contributed in this work.

\section{Ethics}

This study has obtained authorization from the scientific council on behalf of the absence of ethical board in the Department of Dental Medicine.

\section{References}

Cordray, D.S., T.R. Harris and S. Klein, 2009. A research synthesis of the effectiveness, replicability and generality of the VaNTH challenge-based instructional modules in bioengineering. J. Eng. Ed., 98: 335-348.

DOI: 10.1002/j.2168-9830.2009.tb01031.x
Freeman, S., S.L. Eddy, M. McDonough, M.K. Smith and N. Okoroafor et al., 2014. Active learning increases student performance in science, engineering and mathematics. Proc. Nat. Acad. Sci. USA, 111: 8410-8415. DOI: 10.1073/pnas.1319030111

Haukoos, G.D. and J.E. Penick, 1987. Interaction effect of personality characteristics, classroom climate and science achievement. Sci. Educ., 71: 735-743. DOI: 10.1002/sce. 3730710510

Jensen, J.L., T.A. Kummer and P.D.D.M. Godoy, 2015. Improvements from a flipped classroom may simply be the fruits of active learning. CBE Life Sci. Educ., 14: ar5-ar5. DOI: 10.1187/cbe.14-08-0129

LaNoue, M., A. Gentsch, A. Cunningham, G. Mills and A.M.B. Doty et al., 2019. Eliciting patient-important outcomes through group brainstorming: When is saturation reached? J. Patient Rep. Outcomes, 4: 9-9. DOI: 10.1186/s41687-019-0097-2

Ma, Y. and X. Lu, 2019. The effectiveness of problembased learning in pediatric medical education in China. Medicine (Baltimore), 98: e14052-e14052. DOI: 10.1097/MD.0000000000014052

Martin, T., S.D. Rivale and K.R. Diller, 2007. Comparison of student learning in challenge based and traditional instruction in biomedical engineering. Ann. Biomed. Eng., 35: 1312-1323. DOI: $10.1007 / \mathrm{s} 10439-007-9297-7$

Pyburn, D.T., S. Pazicni, V.A. Benassi and E.M. Tappin, 2014. The testing effect: An intervention on behalf of low-skilled comprehenders in general chemistry. J. Chem. Educ., 91: 2045-2057. DOI: $10.1021 / \mathrm{ed} 4009045$

Walker, J.D., S.H. Cotner, P.M. Baepler and M.D. Decker, 2008. A delicate balance: Integrating active learning into a large lecture course. CBE Life Sci. Educ., 7: 361-367. DOI: $10.1187 /$ cbe. 08-02-0004

Wood, D.F., 2003. Problem based learning. BMJ, 326: 328-330. DOI: $10.1136 / \mathrm{bmj} .326 .7384 .328$ 